\title{
PHOTODYNAMIC INACTIVATION OF FOUR CANDIDA SPECIES INDUCED BY PHOTOGEM ${ }^{\circledR}$
}

\author{
Lívia Nordi Dovigo ${ }^{1}$, *Ana Cláudia Pavarina ${ }^{1}$, Daniela Garcia Ribeiro ${ }^{1}$, Cynthia Sanchez Adriano ${ }^{1}$, Vanderlei Salvador \\ Bagnato $^{2}$
}

${ }^{1}$ Universidade Estadual Paulista “Julio de Mesquita Filho”, Faculdade de Odontologia de Araraquara, Departamento de Materiais Odontológicos e Prótese, Araraquara, SP, Brasil; ${ }^{2}$ Universidade de São Paulo, Instituto de Física de São Carlos, São Carlos, SP, Brazil.

Submitted: January 16, 2009; Returned to authors for corrections: June 23, 2009; Approved: August 23, 2009.

\begin{abstract}
This study evaluated the in vitro susceptibility of C. albicans, C. dubliniensis, C. tropicalis and C. krusei to photodynamic therapy (PDT) induced by Photogem ${ }^{\circledR}$ and light emitting diode (LED). Suspensions of each Candida strain were treated with three photosensitizer (PS) concentrations (10, 25 and $50 \mathrm{mg} / \mathrm{L})$ and exposed to 18.0, 25.5 and $37.5 \mathrm{~J} / \mathrm{cm}^{2}$ LED light fluences $(\lambda \sim 455 \mathrm{~nm})$. Control suspensions were treated only with PS concentrations, only exposed to the LED light fluences or not exposed to LED light or PS. Sixteen experimental conditions were obtained and each condition was repeated three times. From each sample, serial dilutions were obtained and aliquots were plated on Sabouraud Dextrose Agar. After incubation of plates $\left(37{ }^{\circ} \mathrm{C}\right.$ for 48 hours), colonies were counted (cfu/mL) and the data were statistically analyzed by ANOVA and the Tukey test $(\alpha=0.05)$. Complete killing of $C$. albicans was observed after 18.0 $\mathrm{J} / \mathrm{cm}^{2}$ in association with $50 \mathrm{mg} / \mathrm{L}$ of PS. C. dubliniensis were inactivated after $18.0 \mathrm{~J} / \mathrm{cm}^{2}$ using $25 \mathrm{mg} / \mathrm{L}$ of PS. The inactivation of $C$. tropicalis was observed after photosensitization with $25 \mathrm{mg} / \mathrm{L}$ and subsequent illumination at $25.5 \mathrm{~J} / \mathrm{cm}^{2}$. For C. krusei, none of the associations between PS and light resulted in complete killing of this species. PDT proved to be effective for the inactivation of C. albicans, C. dubliniensis and C. tropicalis. In addition, reduction in the viability of C. krusei was achieved with some of the PS and light associations.
\end{abstract}

Key words: Photochemotherapy, Candida, Hematoporphyrin Derivative

\section{INTRODUCTION}

Species of the Candida genus are frequently isolated from the oral cavity in the majority of healthy individuals $(24,34)$, living normally in a relationship of commensalism. Nevertheless, these microorganisms can act as opportunist pathogens, invading tissues and setting off infectious processes $(10,23)$. Candida albicans is considered the most prevalent and pathogenic species (27), being present in around $70 \%$ of the cases of oral infections (28). Other species are also frequently associated with the development of infections, such as Candida glabrata, Candida tropicalis, Candida parapsilosis, Candida krusei and Candida guilliermondi (31). In addition to these, there is $C$. dubliniensis, a more recently described species. It has been reported that this species has a virulence similar to that of $C$. albicans, due to their genomic 
similarity (36), and it is frequently isolated in HIV-positive patients (25).

Infection of the oral cavity by Candida spp. is denominated oral candidiasis, and is considered the commonest fungal infection among humans $(1,3)$. For the treatment of this pathology, topical $(2,13)$ and systemic antifungal agents $(8$, 21) can be used. Nevertheless, some studies have demonstrated that the use of these medications could lead to the development of resistance by the Candida species $(17,39)$. Moreover, some species, such as $C$. krusei, are more resistant to fluconazol, in comparison with C. albicans (39).

In view of the difficulties found in treating oral candidiasis (17, 39), many researches have been conducted to seek alternative therapies for the treatment of these infections. A promising therapeutic modality for the inactivation of pathogenic microorganisms is Photodynamic Therapy (PDT) $(9,15,16,29,40,41)$. The photodynamic process requires the use of a chemical compound denominated photosensitizer (PS), the application of a light that corresponds to the absorption band of PS and the presence of oxygen $(19,38)$, promoting the formation of reactive species, such as singlet oxygen (38). The antimicrobial effect of PDT begins when the molecules of PS are irradiated with visible light and the photons are absorbed by the PS. Thereby, an electron is excited from the fundamental state to the singlet state (electrons with paired spins). This electron can return to the fundamental state emitting fluorescence or go on to the triplet state (parallel spins). PS in the triplet state has a relatively long life time, which allows an increase in the number of collisions, still in the excited state, with other molecules (for example, with oxygen). This interaction with neighboring molecules can lead to the formation of the singlet oxygen $\left({ }^{1} \mathrm{O}_{2}\right)$, which is highly reactive in the biological system and can interact with proteins and lipids promoting cell inactivation (18).

The compounds derived from hematoporphyrin $(\mathrm{HpD})$ are PSs widely used in PDT for the treatment of cancer (12), especially Photofrin ${ }^{\circledR}$, Photogem ${ }^{\circledR}$ and Photosan ${ }^{\circledR}$. Some in vitro studies have demonstrated that the topical use of these compounds could also be effective for the photoinactivation of bacteria and fungi $(4,12)$. LED light (42) appears to be a promising light source for PDT because it emits cold light in a narrow band of the spectrum, but at one predominant wavelength. Moreover, it provides spontaneous, non coherent light emission with a certain scattering, the appliance costs less and the technology is simpler in comparison with that of laser appliances (7).

Although studies have analyzed the susceptibility of Candida spp. to PDT $(4,5,12,35)$, the effectiveness of this therapy when associated with Photogem ${ }^{\circledR}$ and LED remains poorly investigated. Therefore, this study evaluated the in vitro photodynamic activity of Photogem ${ }^{\circledR}$ associated with blue LED for inactivating $C$. albicans, C. dubliniensis, C. tropicalis and C. krusei.

\section{MATERIAL AND METHOD}

\section{Preparation of Photogem ${ }^{\circledR}$ and Light Source}

The Photogem ${ }^{\circledR}$ (High Chemical Technology, Moscow, Russia) solution was prepared by dissolving the powder in sterile saline solution. The concentrations of 10,25 and 50 $\mathrm{mg} / \mathrm{L}$ were evaluated. The light source used was an illumination diffusion table, composed by blue LEDs (predominantly $455 \mathrm{~nm}$ ), called Bio Table (Instituto de Física de São Carlos, São Carlos, SP, Brazil). The output power was maintained constant at $12.5 \mathrm{~mW} / \mathrm{cm}^{2}$, and the variation in the fluences of light evaluated was obtained by means of different illumination times (50, 34 and 24 minutes) which resulted in $37.5 ; 25.5$ and $18.0 \mathrm{~J} / \mathrm{cm}^{2}$, respectively.

\section{Microorganisms and growth conditions}

Cell suspensions of reference strains of the species $C$. albicans (ATCC 90028), C. dubliniensis (ATCC 7987), C. tropicalis (ATCC 4563) and C. krusei (ATCC 6258) were used. To obtain the cell suspensions, aliquots of $10 \mu \mathrm{L}$ were removed from frozen cultures and inoculated individually in 5 mL of Tryptic Soy Broth (TSB; Acumedia Manufactures, Inc. Baltimore, Maryland 21220, EUA) contained in test tubes. The test tubes were incubated at $37{ }^{\circ} \mathrm{C}$ for 16 hours. After the 
incubation period, the cells were collected by centrifugation and resuspended in sterile saline solution until the cell concentration inside the test tube was equivalent to $10^{6}$ cells/mL (McFarland scale).

\section{Experimental conditions}

For each microorganism, nine experimental conditions were tested, obtained by crossing the three concentrations of PS and three doses of light. These experimental conditions were denominated $\mathrm{P}+\mathrm{L}+$. Thus, using a 96-well plate, aliquots of $100 \mu \mathrm{L}$ of the cell suspensions of each species were photosensitized with the same volume of Photogem ${ }^{\circledR}(100 \mu \mathrm{L})$, at one of the concentrations evaluated. The well plate containing the resulting suspensions was left to rest in the dark for 30 minutes, and after this was placed on the Bio Table illumination surface. These procedures were performed to evaluate the three fluences of light proposed in this study (37.5; 25.5 and $18.0 \mathrm{~J} / \mathrm{cm}^{2}$ ).

Furthermore, the effect of the isolated application of each concentration of Photogem $^{\circledR}(\mathrm{P}+\mathrm{L}-)$ and of each light fluence (P-L+) was also evaluated. Additional samples of the control group were not photosensitized with Photogem ${ }^{\circledR}$ or illuminated with LED (P-L-), totaling 15 experimental conditions and 1 control conditions for each Candida species.

For all the conditions evaluated, serial dilutions from $10^{-1}$ to $10^{-3}$ were obtained from the samples contained in the wells. These serial dilutions were plated on Sabouraud Dextrose Agar with $5 \mu \mathrm{g} / \mathrm{mL}$ of gentamicin (SDA; Acumedia Manufactures, Inc. Baltimore, Maryland 21220, EUA). In addition, aliquots of $25 \mu \mathrm{L}$ were removed from the cavities of the well plates and transferred directly to the SDA, without being diluted. After 48 hours of incubation at $37{ }^{\circ} \mathrm{C}$, the Petri plates were submitted to colony counting and the numbers of colony forming units were calculated.

\section{Statistical analysis}

For each condition evaluated in this study, three repetitions were performed. Sample plating was performed in triplicate for better characterization of the value obtained.
Analysis of variance - ANOVA was performed to evaluate only the values obtained under the conditions P-L-, P+L- and $\mathrm{P}-\mathrm{L}+$ of these species. The results obtained for $C$. krusei made it possible to perform ANOVA to evaluate all the experimental conditions (P-L-, $\mathrm{P}+\mathrm{L}-, \mathrm{P}-\mathrm{L}+$ and $\mathrm{P}+\mathrm{L}+)$, bearing in mind that all experimental conditions resulted in colony growth. In all the cases, when ANOVA pointed towards the existence of statistically significant difference, the Tukey HSD post hoc test was performed $(\alpha=0.05)$ (33).

\section{RESULTS}

After incubation $\left(48\right.$ hours $\left./ 37^{\circ} \mathrm{C}\right)$, the control plates (P-L-) of the four Candida species showed abundant growth of viable colonies. It was observed that the effect of the isolated application of the three concentrations of PS (P+L-) did not significantly alter the number of cfu/mL for the four species, in comparison with the values obtained in the control groups $(p>0.05)$. On the other hand, the isolated application of the three light fluences (P-L+) on the four species resulted in significantly lower $\mathrm{cfu} / \mathrm{mL}$ values $(p<0.05)$ in comparison with those obtained in the control group (Table 1).

For all the species evaluated, a significant reduction in the number of $\mathrm{cfu} / \mathrm{mL}$ was observed after the application of PDT. The effectiveness of the therapy in reducing cell viability varied as a function of the microorganism and the association between Photogem ${ }^{\circledR}$ and the fluence of light (Fig. 1). $C$. albicans, C. dubliniensis and C. tropicalis showed no microbiologic growth (48 hours $/ 37^{\circ} \mathrm{C}$ ) after PDT, indicating the complete inactivation of these microorganisms (Table 2). Bearing in mind that certain associations of the conditions $\mathrm{P}+\mathrm{L}+$ for $C$. albicans, $C$. tropicalis and $C$. dubliniensis species showed no survival, it was impossible to make statistical inference. The minimum fluence of light necessary to achieve total inviability of $C$. albicans was $18.0 \mathrm{~J} / \mathrm{cm}^{2}$ associated with $50 \mathrm{mg} / \mathrm{L}$ of PS. In a similar manner, $C$. dubliniensis was also inactivated with illumination of $18.0 \mathrm{~J} / \mathrm{cm}^{2}$, but the concentration of PS required was $25 \mathrm{mg} / \mathrm{L}$. The inactivation of C. tropicalis occurred with illumination of $25.5 \mathrm{~J} / \mathrm{cm}^{2}$ associated with $25 \mathrm{mg} / \mathrm{L}$ of PS. 
Table 1. Mean colony-forming unit $(\mathrm{cfu} / \mathrm{mL})$ values of each Candida species obtained under $\mathrm{P}-\mathrm{L}+, \mathrm{P}+\mathrm{L}-\mathrm{and}$ the control conditions.

\section{Control conditions}

\begin{tabular}{|c|c|c|c|c|c|c|c|}
\hline & \multirow[t]{2}{*}{ P-L- } & \multicolumn{3}{|c|}{$\mathrm{P}+\mathrm{L}-$} & \multicolumn{3}{|c|}{ P-L+ } \\
\hline & & $10 \mathrm{mg} / \mathrm{L}$ & $25 \mathrm{mg} / \mathrm{L}$ & $50 \mathrm{mg} / \mathrm{L}$ & $18.0 \mathrm{~J} / \mathrm{cm}^{2}$ & $25.5 \mathrm{~J} / \mathrm{cm}^{2}$ & $37.5 \mathrm{~J} / \mathrm{cm}^{2}$ \\
\hline C. albicans & $5.50 \mathrm{E}+14^{\mathrm{a}}$ & $6.23 \mathrm{E}+06^{a}$ & $5.91 \mathrm{E}+06^{\mathrm{a}}$ & $5.71 \mathrm{E}+06^{\mathrm{a}}$ & $3.27 \mathrm{E}+06^{b}$ & $3.17 \mathrm{E}+06^{b}$ & $3.19 \mathrm{E}+06^{\mathrm{b}}$ \\
\hline C. dubliniensis & $2.67 \mathrm{E}+06^{\mathrm{a}}$ & $2.71 \mathrm{E}+06 \mathrm{a}$ & $3.13 \mathrm{E}+06^{\mathrm{a}}$ & $2.70 \mathrm{E}+06^{\mathrm{a}}$ & $4.17 \mathrm{E}+05 \mathrm{~b}$ & $4.23 \mathrm{E}+05^{\mathrm{b}}$ & $4.00 \mathrm{E}+05 \mathrm{~b}$ \\
\hline C. tropicalis & $1.77 \mathrm{E}+06^{\mathrm{a}}$ & $1.75 \mathrm{E}+06^{\mathrm{a}}$ & $1.60 \mathrm{E}+06^{\mathrm{a}}$ & $1.70 \mathrm{E}+06^{\mathrm{a}}$ & $2.52 \mathrm{E}+05^{\mathrm{b}}$ & $2.97 \mathrm{E}+05^{\mathrm{b}}$ & $2.75 \mathrm{E}+05^{\mathrm{b}}$ \\
\hline C. krusei & $2.29 \mathrm{E}+06^{\mathrm{a}}$ & $2.13 \mathrm{E}+06^{\mathrm{a}}$ & $2.34 \mathrm{E}+06^{\mathrm{a}}$ & $2.36 \mathrm{E}+06^{\mathrm{a}}$ & $4.19 \mathrm{E}+05^{\mathrm{b}}$ & $4.18 \mathrm{E}+05^{b}$ & $4.63 \mathrm{E}+05 \mathrm{~b}$ \\
\hline
\end{tabular}

$\mathrm{E}+06$ and $\mathrm{E}+05=10^{6}$ and $10^{5}$, respectively. Horizontally, identical superscripted small letters denote no significant differences among groups ( $\mathrm{p}>0.05$ ). No comparisons were made among Candida species.

A

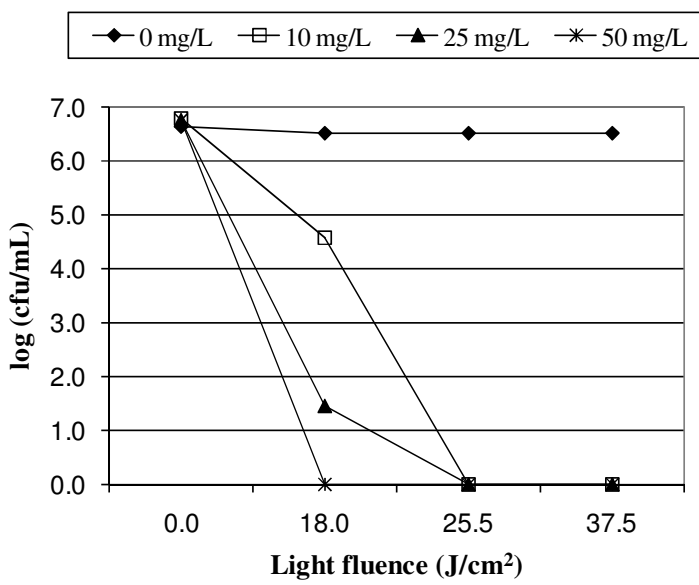

C

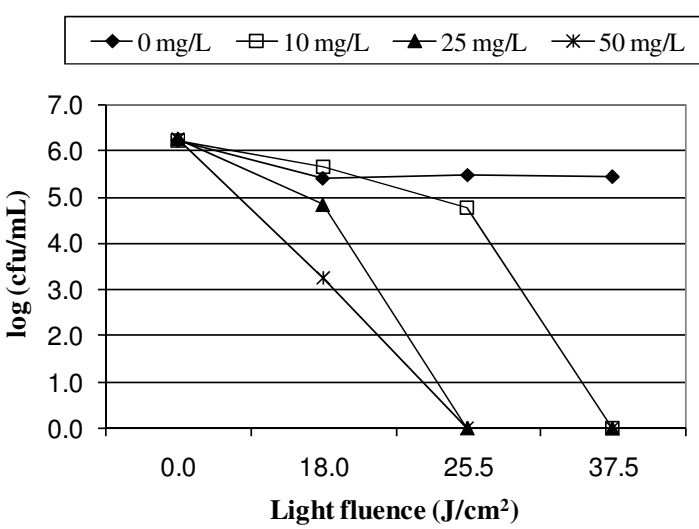

B

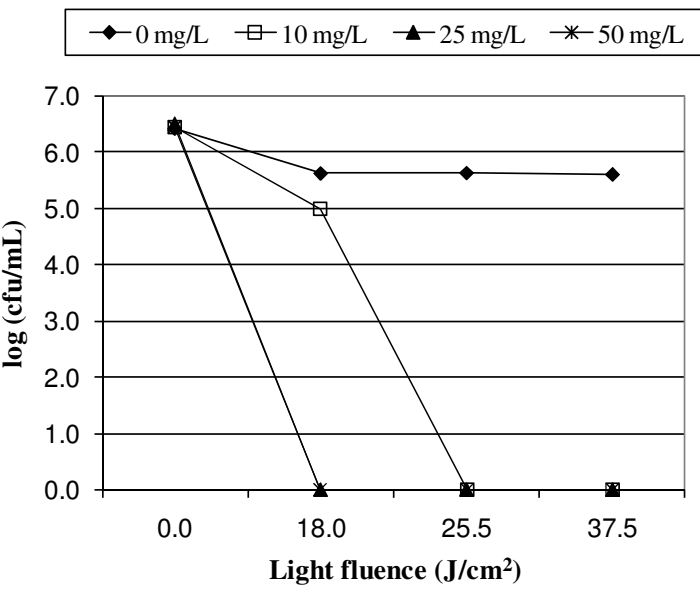

D

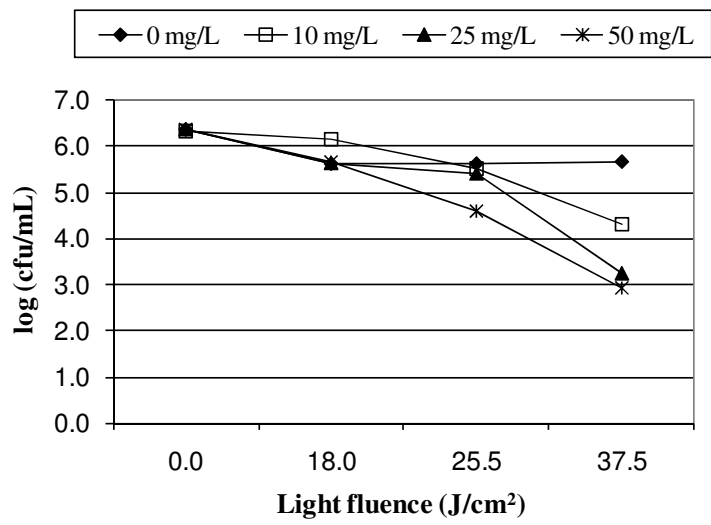

Figure 1. Graphic representation of the values from logarithmic of survival counts $(\mathrm{cfu} / \mathrm{mL})$ of $C$. albicans (A), C. dubliniensis (B), C. tropicalis (C) e C. krusei (D). 
Dovigo, L.N. et al.

Table 2. Minimal Photogem ${ }^{\circledR}$ concentration $(\mathrm{mg} / \mathrm{L})$ for photoinactivation of C. albicans, C. dubliniensis and C. tropicalis.

\begin{tabular}{|c|c|c|c|}
\hline \multirow{2}{*}{$\begin{array}{l}\text { Light fluence } \\
\left(\mathrm{J} / \mathrm{cm}^{2}\right)\end{array}$} & \multicolumn{3}{|c|}{ Minimal lethal concentration $(\mathrm{mg} / \mathrm{L})$} \\
\hline & C. albicans & C. dubliniensis & C. tropicalis \\
\hline 18.0 & 50 & 25 & - \\
\hline 25.5 & 10 & 10 & 25 \\
\hline 37.5 & 10 & 10 & 10 \\
\hline
\end{tabular}

For C. krusei, the results showed a significant reduction in cell viability (Fig. 1D). No association of PS and light resulted in complete inactivation of $C$. krusei (Fig. 1D). When the fluence of $18.0 \mathrm{~J} / \mathrm{cm}^{2}$ was evaluated, the use of PS at the concentrations of 50 and $25 \mathrm{mg} / \mathrm{L}$ resulted in similar $\mathrm{cfu} / \mathrm{mL}$ values, which were statistically lower than the value obtained in the control group $(p<0.05)$. Whereas, when the samples were illuminated at 25.5 or $37.5 \mathrm{~J} / \mathrm{cm}^{2}$, the three concentrations of FS $(50,25$ and $10 \mathrm{mg} / \mathrm{L})$ resulted in $\mathrm{cfu} / \mathrm{mL}$ values that were statistically lower than those of the control group $(p<0.05)$.

\section{DISCUSSION}

This study evaluated the in vitro susceptibility of four Candida species to PDT by means of the association of three concentrations of Photogem ${ }^{\circledR}$ and three fluences of LED light. One of the most significant findings was the complete inviability of the suspensions of $C$. albicans, $C$. dubliniensis and $C$. tropicalis. For the three species, the use of high fluences of light promoted photoinactivation with low concentrations of Photogem $^{\circledR}$. These results were considered relevant, since a few investigations observed the total elimination of $C$. albicans after PDT $(22,37)$, while the photoinactivation of $C$. dubliniensis and $C$. tropicalis is a completely new result. In the study of Lambrechts et al. (22), the in vitro use of a cationic porphyrin $(25 \mu \mathrm{M})$ associated with $12.6 \mathrm{~J} / \mathrm{cm}^{2}$ of halogen light resulted in the absence of viable colonies of $C$. albicans after 48 hours of incubation. In another study, methylene blue dye was also effective in photosensitizing $C$. albicans, promoting the complete elimination of this microorganism from the oral cavity of immunosuppressed rats after illumination with 275 $\mathrm{J} / \mathrm{cm}^{2}$ of diode laser (37). Although the authors used higher concentrations of PS $(450 \mathrm{mg} / \mathrm{L}$ to $500 \mathrm{mg} / \mathrm{L})$ for the total inactivation of $C$. albicans, the above-mentioned study was conducted in vivo (37). This fact could justify the need for the use of high concentrations of PS and fluences. In the present study, a similar inactivation behavior was also observed between $C$. albicans and $C$. dubliniensis. The latter is a more recently described species of Candida that has greater incidence in patients with AIDS and is not always eliminated with the use of antifungal agents (36). The two species have almost identical phenotypical characteristics, as well as genetic similarities (36) which could explain the similar result obtained with the application of PDT.

Bearing in mind that the photodynamic action requires an association of PS and light, the application of light without the presence of a PS is not capable of promoting the formation of singlet oxygen. It is fundamental to have the presence of a substance to intermediate the process of reactive species formation. However, the results of condition P-L+ showed statistically significant differences, when compared with the control group, suggesting a possible toxic effect of the light. Souza et al. (35) observed that the isolated application of laser also caused a reduction in the $\mathrm{cfu} / \mathrm{mL}$ values of $C$. tropicalis. It has been reported that cell irradiation with visible light and its consequent absorption by the tissue molecules could cause both a proliferative and inhibitive effect, and is elucidated by two processes that involve electronic excitation. One of the processes is the transfer of energy to oxygen, since the cytochrome works as photosensitizer, enabling the 
photodynamic damage to occur without the presence of an external photosensitizer (20).

For C. krusei, no results similar to those of the other species were obtained, once this microorganism was not completely inactivated under any experimental condition. Nevertheless, under the conditions in which PDT was evaluated, significantly lower cfu/mL values were observed in comparison with the control group. The susceptibility of $C$. krusei to PDT can be considered an important result since this microorganism has frequently been isolated in immunocompromised patients, particularly when there were reports of previous exposure to fluconazol $(11,26)$. Its main characteristic is intrinsic resistance to various antifungal medications, such as fluconazol, which makes it difficult to treat infections by C. krusei (30). In the present study, the greatest reduction in the viability of C. krusei was obtained after the use of $50 \mathrm{mg} / \mathrm{L}$ of Photogem ${ }^{\circledR}$, associated with 37.5 $\mathrm{J} / \mathrm{cm}^{2}$ of illumination. Bliss et al. (5) observed a concentrationdependent curve when Photofrin ${ }^{\circledR}$ was evaluated for photosensitizing C. albicans and C. krusei. These authors also found that $C$. krusei was more resistant to PDT, when compared with $C$. albicans (5). Although it has previously been observed that $C$. krusei was more resistant to being photosensitized, the reasons that lead to this behavior have not yet been explained. Particularly with regard to C. albicans, the photochemical processes mediated by hematoporphyrin derivatives, initially appear to promote an alteration in the cytoplasmatic membrane of the microorganism (4). This effect possibly occurs through oxidative alterations in lipids and proteins present in the membrane (6). Afterwards, PS is able to penetrate into the cell and cause irreversible damage to the intracellular organelles, which leads to cellular inactivation (4). According to Jori et al. (19), the increase in the permeability of the membrane during the initial photochemical processes is fundamental for accentuating the photodynamic effect on fungal cells, as inactivation effectively occurs after the uptake of PS into the cell interior. It can be supposed that some of the peculiarities inherent to $C$. krusei could act as resistance to cell inactivation by photochemical processes, as is the case with
PDT. It has been suggested that C. krusei has greater superficial hydrophobicity in comparison with $C$. albicans (32). This characteristic is responsible for C. krusei cells to have a greater tendency to adhere to each other when in the yeast form. In order for the photodynamic effect to occur, it is necessary for singlet oxygen to be formed close to its target, due to its short life time and low diffusion capacity in water (6). Therefore, the phenomenon of co-adhesion among the $C$. krusei cells adhering to each other could be associated with difficulty singlet oxygen has in attaining the surface of fungal cells, thus diminishing the effectiveness of the therapy. Nevertheless, no specific information was found in the literature.

It is important to point out that the inactivation of the Candida species by PDT could present important advantages over conventional treatments considering that antifungal medications frequently do not completely eliminate the Candida species $(2,8,14)$. Therefore, the photoinactivation results observed in the present study could suggest PDT as an effective method for fungal inactivation, which would contribute to overcoming the limitations of conventional medications and provide better treatment results. However, the experiments of this study were conducted with planktonic cultures of the microorganisms, which may not faithfully simulate the conditions found in vivo. Clinically, the microorganisms are found grouped into complex communities, denominated microbial biofilms $(13,42)$. Chabrier-Roselló et al. (12) demonstrated a significant reduction in the metabolic activity of $C$. albicans biofilms after photosensitization with 10 $\mathrm{mg} / \mathrm{L}$ of Photofrin $^{\circledR}$ and illumination at $18 \mathrm{~J} / \mathrm{cm}^{2}$. The elimination of $C$. albicans present on rat tongues has also been demonstrated with the use of methylene blue and laser (37). Therefore, the effective use of PDT, in vivo, appears to be a promising field of study, and the results of the present study may serve as a parameter for future investigations, in which the association of Photogem ${ }^{\circledR}$ with LED could be evaluated in situations that simulate the conditions found clinically.

Considering the limitations of the present study, it was concluded that PDT presented a fungicidal effect on fungal 
suspensions, being effective in the inactivation of the $\mathrm{C}$. albicans, C. dubliniensis and C. tropicalis species, and in the significant reduction in the cell viability of C. krusei.

\section{ACKNOWLEDGMENTS}

This research was supported financially by $\mathrm{CNPq}$ (Conselho Nacional de Desenvolvimento Científico e Tecnológico).

\section{REFERENCES}

1. Akpan, A.; Morgan R. (2002). Oral candidiasis. Postgrad. Med. J. 78, 455-459.

2. Banting, D.W.; Greenhorn, P.A.; McMinn, J.G. (1995). Effectiveness of a topical antifungal regimen for the treatment of oral candidiasis in older, chronically ill, institutionalized, adults. J. Can. Dent. Assoc. 61, 199-200, 203-5.

3. Banting, D.W.; Hill, S.A. (2001). Microwave disinfection of dentures for the treatment of oral candidiasis. Spec. Care Dentist. 21, 4-8.

4. Bertoloni, G.; Reddi, E.; Gatta, M.; Burlini, C.; Jori, G. (1989). Factors influencing the haematoporphyrin-sensitized photoinactivation of Candida albicans. J. Gen. Microbiol. 135, 957-966.

5. Bliss, J.M.; Bigelow, C.E.; Foster, T.H.; Haidaris, C.G. (2004) Susceptibility of Candida species to photodynamic effects of Photofrin. Antimicrob. Agents. Chemother. 48, 2000-2006.

6. Bocking, T.; Barrow, K.D.; Netting, A.G.; Chilcott, T.C.; Coster, H.G.L.; Hofer, M. (2000). Effects of singlet oxygen on membrane sterols in the yeast Saccharomyces cerevisiae. Eur. J. Biochem. 267, 1607-1618.

7. Brancaleon, L.; Moseley, H. (2002). Laser e non-laser light sources for Photodynamic Therapy. Lasers Med. Sci. 17, 173-186.

8. Budtz-Jorgensen, E.; Holmstrup, P.; Krogh, P. (1988). Fluconazole in the treatment of Candida-associated denture stomatitis. Antimicrob. Agents Chemother. 32, 1859-1863.

9. Burns, T.; Wilson, M.; Pearson, G.J. (1994). Killing of cariogenic bacteria by light from a gallium aluminium arsenide diode laser. J. Dent. 22, 273-278.

10. Calderone, R.A.; Fonzi, W.A. (2001). Virulence factors of Candida albicans. Trends Microbiol. 9, 327-335.

11. Cartledge, J.D.; Midgley, J.; Gazzard, B.G. (1999). Non-albicans oral candidosis in HIV-positive patients. J. Antimicrob. Chemother. 43, 419422.

12. Chabrier-Rosello, Y.; Foster, T.H.; Perez-Nazario, N.; Mitra, S.; Haidaris, C.G. (2005). Sensitivity of Candida albicans germ tubes and biofilms to photofrin-mediated phototoxicity. Antimicrob. Agents Chemother. 49, 4288-4295.
13. Chandra, J.; Kuhn, D.M.; Mukherjee, P.K.; Hoyer, L.L.; McCormick, T.; Ghannoum, M.A. (2001). Biofilm formation by the fungal pathogen Candida albicans: development, architecture, and drug resistance. J. Bacteriol. 183, 5385-5394.

14. Chandra, J.; Mukherjee, P.K.; Leidich, S.D.; Faddoul, F.F.; Hoyer, L.L.; Douglas, L.J.; Ghannoum, M.A. (2001). Antifungal resistance of candidal biofilms formed on denture acrylic in vitro. J. Dent. Res. 80, 903-908.

15. DeSimone, N.A.; Christiansen, C.; Dore, D. (1999). Bactericidal effect of $0.95-\mathrm{mW}$ helium-neon and 5-mW indium-gallium-aluminum-phosphate laser irradiation at exposure times of 30, 60, and 120 seconds on photosensitized Staphylococcus aureus and Pseudomonas aeruginosa in vitro. Phys. Ther. 79, 839-846.

16. Dobson, J.; Wilson, M. (1992). Sensitization of oral bacteria in biofilms to killing by light from a low-power laser. Arch. Oral Biol. 37, 883-887.

17. Goldman, G.H.; da Silva Ferreira, M.E.; dos Reis Marques, E.; Savoldi, M.; Perlin, D.; Park, S.; Godoy Martinez, P.C.; Goldman, M.H.; Colombo, A.L. (2004). Evaluation of fluconazole resistance mechanisms in Candida albicans clinical isolates from HIV-infected patients in Brazil. Diagn. Microbiol. Infect. Dis. 50, 25-32.

18. Henderson, B.W.; Dougherty, T.J. (1992). How does photodynamic therapy work? Photochem Photobiol. 55, 145-157.

19. Jori, G.; Fabris, C.; Soncin, M.; Ferro, S.; Coppellotti, O.; Dei, D.; Fantetti, L.; Chiti, G.; Roncucci, G. (2006). Photodynamic therapy in the treatment of microbial infections: basic principles and perspective applications. Lasers Surg. Med. 38, 468-481.

20. Karu, T. (1989). Photobiology of low-power laser effects. Health Phys. 56, 691-670.

21. Kulak, Y.; Arikan, A.; Delibalta, N. (1994). Comparison of three different treatment methods for generalized denture stomatitis. $J$. Prosthet. Dent. 72, 283-288.

22. Lambrechts, S.A.G.; Aalders, M.C.G.; Van Marle, J. (2005). Mechanistic study of the photodynamic inactivation of Candida albicans by cationic porphyrin. Antimicrob. Agents Chemother. 49, 2026-2034.

23. Lyon, J.P.; Moreira, L.M.; Cardoso, M.A.G.; Saade, J.; Resende M.A. (2008). Antifungal suscepitibility profile of Candida spp. oral isolates obtained from denture wearers. Braz. J. Microbiol. 39, 668-672.

24. Martins, C.A.P.; Koga-Ito, C.Y.; Jorge, A.O.C. (2002). Presence of Staphylococcus spp. and Candida spp. in the human oral cavity. Braz. J. Microbiol. 33, 236-240.

25. Melo, N.R.; Taguchi, H.; Culhari, V.V.P.; Sano, A.; Fukushima, K.; Miyaji, M.; Manning, N.; Kelly, S.L.; Vilela, M.M.S. (2006). Candida dubliniensis in a brazilian family with an hiv 1- infected child: identification, antifungal susceptibility, drug accumulation and sterol composition. Braz. J. Microbiol. 37, 237-243.

26. Muñoz, P.; Sánchez-Somolinos, M.; Alcalá, L.; Rodríguez-Créixems, M.; Peláez, T.; Bouza, E. (2005). Candida krusei fungaemia: antifungal susceptibility and clinical presentation of an uncommon entity during 15 years in a single general hospital. J. Antimicrob. Chemother. 55, 188-193. 
27. Neves, R.P; Cavalcante, M.A.Q; Chaves, G.M.; Magalhães, O.M.C. (2002). Yeasts isolated from clinical samples of aids patients. Braz. J. Microbiol. 33, 363-364.

28. Nikawa, H.; Hamada, T.; Yamamoto, T. (1998). Denture plaque-past and recent concerns. J. Dent. 26, 299-304.

29. Okamoto, H.; Iwase, T.; Morioka, T. (1992). Dye-mediated bactericidal effect of He-Ne laser irradiation on oral microorganisms. Lasers Surg. Med. 12, 450-458.

30. Pfaller, M.A.; Diekema, D.J.; Gibbs, D.L.; Newell, V.A.; Nagy, E.; Dobiasova, S.; Rinaldi, M.; Barton, R.; Veselov, A. (2008). Candida krusei, a multidrug-resistant opportunistic fungal pathogen: geographic and temporal trends from the ARTEMIS DISK Antifungal Surveillance Program, 2001 to 2005. J. Clin. Microbiol. 46, 515-521.

31. Samaranayake, Y.H.; Samaranayake, L.P. (2001). Experimental oral candidiasis in animal models. Clin. Microbiol. Rev. 14, 398-429.

32. Samaranayake, Y.H.; Wu, P.C.; Samaranayake, L.P.; So, M. (1995). Relationship between the cell surface hydrophobicity and adherence of Candida krusei and Candida albicans to epithelial and denture acrylic surfaces. APMIS. 103, 707-713.

33. Sokal, R.R.; Rohlf, F.J. (1995) Biometry: the principles and practice of statistics in biological research. W.H. Freeman and Co., New York.

34. Soll, D.R. (2002). Candida commensalism and virulence: the evolution of phenotypic plasticity. Acta Trop. 81, 101-110.

35. Souza, S.C.; Junqueira, J.C.; Balducci, I.; Koga-Ito, C.Y.; Munin, E.;
Jorge, A.O.C. (2006). Photosensitization of different Candida species by low power laser light. J. Photochem. Photobiol. B. 83, 34-38.

36. Sullivan, D.J.; Westerneng, T.J.; Haynes, K.A.; Bennett, D.E.; Coleman, D.C. (1995). Candida dubliniensis sp. nov.: phenotypic and molecular characterization of a novel species associated with oral candidosis in HIV-infected individuals. Microbiology. 141, 1507-1521.

37. Teichert, M.C.; Jones, M.D.; Usacheva, M.N.; Biel, M.A. (2002). Treatment of oral candidiasis with methylene blue-mediated photodynamic therapy in an immunodeficient murine model. Oral Surg. Oral Med. Oral Pathol. Oral Radiol. Endod. 93, 155-160.

38. Wainwright, M. (1998). Photodynamic antimicrobial chemotherapy (PACT). J. Antimicrob. Chemother. 42, 13-28.

39. White, T.C.; Marr, K.A.; Bowden, R.A. (1998). Clinical, cellular and molecular factors that contribute to antifungal drug resistance. Clin. Microbiol. Rev. 11, 382-402.

40. Wilson, M.; Mia, N. (1994). Effect of environmental factors on the lethal photosensitization of Candida albicans in vitro. Lasers Med. Sci. 9, 105109.

41. Wilson, M.; Mia, N. (1993). Sensitisation of Candida albicans to killing by low-power laser light. J. Oral Pathol. Med. 22, 354-357.

42. Zanin, I.C.J.; Gonçalves, R.B.; Brugnera Jr, A.; Hope, C.K.; Pratten, J. (2005). Susceptibility of Streptococcus mutans biofilms to photodynamic therapy: an in vitro study. J. Antimicrob. Chemother. 56, 324-330. 